

\section{Resgatando os fundadores}

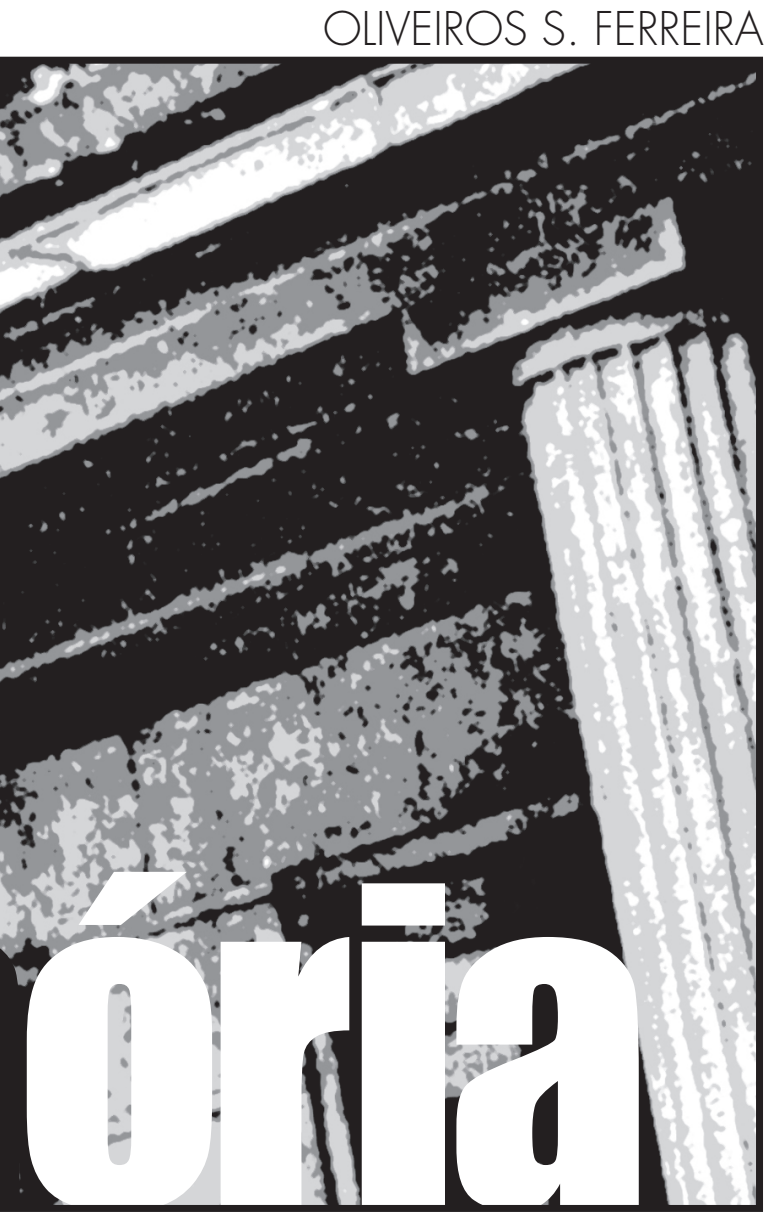

OLIVEIROS S.

FERREIRA é professor do

Departamento de Sociologia da FFLCH-USP e autor de, entre outros, Vida e Morte do Partido Fardado (Senac).
Nem sempre a paisagem que se vê, quando se lança 0 olhar para trás, meio século ou um pouco mais depois, assemelha-se a uma fotografia, mesmo que retocada. Os anos turvaram a visão, quando não seu alcance, e aquilo que vislumbramos é apenas o que a memória, traiçoeiramente, nos leva a ver. Eé desses fragmentos em que luz e sombra se misturam a tal ponto que muitas vezes aquilo que se vê escuro foi claro - mas como escuro foi gravado na memória e como escuro será sempre lembrado - que a memória histórica se compõe. 0 que não significa que aquilo que se vê claro, hoje, tenha sido assim; quantas vezes a luz se turvou pela emoção que trazia lágrimas aos olhos que então viam fudo de maneira diferente porque filtrada pelo sentimento. É com essa consciência que olho para trás nestes 70 anos da Universidade de São Paulo; mais do que dela, da Faculdade, hoje de Filosofia, Letras e Ciências Humanas, mas que foi como de Filosofia, Ciências e Letras que conquistou seu lugar ao sol junto às demais que passaram a integrar a Universidade, e foi como de Ciências e Letras que se afirmou na paisagem intelectual, primeiro de São Paulo, depois do Brasil, nem sempre compreendida, nem sempre compreendendo os outros, os que não pertenciam à grei dos escolhidos.

Falar da Faculdade sem falar na coterie em que ela se constituiu logo depois de sua criação é fazer da história um edifício sem as paredes que o separam da cidade, mas que ao mesmo tempo atestam que a ela pertence. A idéia de coterie, sempre a tomei do Marx do 18 Brumário, nele referida de passagem como a indicar uma "fração de classe", daquelas que, para ele, eram a chave para a compreensão do fenômeno Luís Napoleão. Era a fração que se reunia em torno do National e que, pelas características de seus membros, não podia ser dada como uma fração de classe igual às outras em que então se dividia o espectro político da França de 1852. Que era ela? Quem a integrava? A descrição que Marx faz da "fração republicana" no 18 Brumário confirma a importância que ele emprestava à posição social e não à propriedade na definição do que fosse fração de classe. Para ele, a posição do National "sob a monarquia constitucional estava de acordo com seu caráter. Esta 
não era uma fração da burguesia liberal ligada por grandes interesses comuns e separada das demais por condições de produção a ela peculiares; era um círculo social restrito de membros da burguesia com idéias republicanas: escritores, advogados, oficiais e funcionários públicos. Sua influência decorria da antipatia pessoal do país por Luis Felipe, de memórias da velha república, da fé republicana de um número de entusiastas e, acima de tudo, do nacionalismofrances [...]". (A palavra coterie vem do francês, significando reunião de pessoas íntimas. No inglês, que registra igualmente coterie, é dada por um grupo íntimo, muitas vezes exclusivo de pessoas com um interesse comum. Marx a usa no alemão: Koterie. Fiquemos, por instantes que sejam, com o inglês.)

A coterie é um grupo restrito de pessoas que têm um interesse comum, independentemente de sua condição ou situação de classe, como a definiria a sociologia. O que nos remete, ao não considerar a situação de classe, ao interesse comum. Esse não pode ser material; sendo assim, é político em sentido amplo e, na extremidade (lembremo-nos de Clausewitz), corresponde a uma visão do mundo. Digo "visão" e não "concepção" porque aquela é mais restrita do que esta, embora a visada possa influenciar a idéia geral que o ator social faz do campo sociopolítico em que deverá agir. Ao preferir "visão" a "concepção" reduzo sem dúvida o campo em que se situam os interesses comuns das pessoas que se reúnem na coterie; mas é exatamente isto que tenho em vista. O que pretendo deixar assinalado é que a Faculdade de Filosofia, Ciências e Letras era uma coterie porque havia uma reunião de pessoas que se aproximavam porque tinham um interesse comum, independente de posições que tinham diante de outros problemas da cidade. O National define bem o que tenho em mente: o interesse dos que se reuniam em torno dele era o "nacionalismo francês", o que significava que poderiam tomar posições contrárias diante de problemas outros que não tocassem, ainda que tangencialmente, o cerne do que se tinha por "nacionalismo".
Na paisagem que vislumbro da colina a que os anos me trouxeram, vejo que a coterie da Faculdade de Filosofia, Ciências e Letras melhor seria designada se a chamássemos de "coterie Estado de S. Paulo", jornal. Ou, para ser mais preciso, Júlio de Mesquita Filho. Não exagero. Para as jovens gerações - as que vieram depois de 1964, que separou definitivamente as pessoas que faziam da Faculdade o que era e sem ato autoritário algum, pelo simples efeito de presença, liquidou a coterie - soará estranho tudo o que disse. Como para mim soaram estranhas as palavras de um professor de geografia, já aposentado, que ao recordar os anos de ouro se referia à "Faculdade dos Mesquita" (que combatera por ser “isto"), lembrando que durante anos houvera quem se propusesse fechá-la. Palavras que mostravam como eram reveladoras as palavras de antigo professor da Faculdade, recordando-se de que o interventor Ademar de Barros pretendera fechá-la, porque incomodava a cidade - mas seguramente, ele não disse, porque ela fora criada por Armando de Salles Oliveira que se opusera ao Partido Republicano Paulista e o desbaratara em seu governo como interventor de Getúlio Vargas, depois governador constitucional.

Por que uma coterie? Que interesse comum unia seus membros? A "intimidade" não decorria de uma comunidade de vida anterior à criação da Faculdade; vinha de uma estranha relação que o jornal (que era expressão da vontade de Júlio de Mesquita Filho) guardava com a Universidade e, em especial, com a Faculdade. Ele, Júlio, inspirara a criação da Universidade e, especialmente, da Faculdade de Filosofia. Ele dera a contribuição de suas relações pessoais e de seu prestígio, em 1934, para a composição do corpo docente de diferentes áreas. A Universidade e, mais do que ela, a Faculdade, era como seu filho e a ele se devotava-e seus adversários políticos, que não vinham apenas do Estado Novo, mas já de antes, da cisão do Partido Republicano (ou teria sido a cisão na Bucha?) de que resultara a criação do Partido Democrático em 1924, tinham plena consciência de que 
ela era "sua" criação. Júlio de Mesquita Filho e o grupo que o cercara no período dos governos de Armando tinham como evidente que a Faculdade era o instrumento para produzir a transformação das mentalidades que reputavam necessária para fazer que o Brasil se transformasse em Nação, vencendo a "horda" e o "caudilhismo" que haviam tomado conta do poder em 1930. As forças sociais organizadas que representavam aquilo que Marx chamava de "Partido da Ordem" - e que tinham por lema "Família, Propriedade, Religião, Ordem" - podiam rir-se da visão abrasileirada da horda de Durkheim e não aceitar que Vargas fosse um caudilho, mas sabiam aquilo a que a Faculdade se propunha na visão do Estado de S. Paulo. Por isso se dispunham a fechá-la ou, na impossibilidade, a fazer que não cumprisse a missão transformadora de mentalidades para a qual fora criada. Algum representante do Partido da Ordem, no fim dos anos 30 e começo dos 40 , poderia considerar como cultores de sua forma mentis e de sua concepção do mundo (agora, sim, uma verdadeira Weltanschauung) os professores de filosofia, política, história, sociologia, antropologia e até mesmo de literatura que vinham da França laica ou se esquivando à Itália fascista? Eles sabiam, antes que se falasse em Gramsci no Brasil, que a "faculdade dos Mesquita" poderia oferecer "um princípio educativo e pedagógico original" que permitiria aos alunos que nela estudassem ter uma "concepção geral da vida, uma filosofia (Gioberti) que oferec[esse] aos aderentes uma 'dignidade intelectual'" que desse um " princípio de distinção e um elemento de luta contra as velhas ideologias dominantes coercitivamente". Os representantes do Partido da Ordem sabiam que a disputa era pela "direção intelectual e moral" do processo, pela hegemonia, como se diria hoje. Por isso, não podendo fechar a Faculdade, cuidavam de impedir que seus "adversários" chegassem aos postos de comando. Não se dizia, naqueles anos turbulentos e já esquecidos, que o cardeal arcebispo de São Paulo tinha manifestado com vigor seu grande interesse em que
Antonio Candido não fosse o catedrático de literatura brasileira?

$\mathrm{O}$ interesse comum que aproximava o Estado e um grupo de catedráticos e assistentes era a preservação da escola. Que poderiam entender de "horda" $\mathrm{e}$ "caudilhismo gaúcho", Mogüé, Roger e PaulArbousse Bastide, Lévy-Strauss, Hugon e tantos outros que vinham simplesmente nos transmitir o "verdadeiro método de ensinar"? Cuidavam era de formar os futuros professores do ensino secundário e normal, um dos objetivos da Faculdade. Era em torno desse objetivo que se travava a grande disputa que passava desapercebida pela cidade: formar os professores do ensino secundário e normal; transmitir "um princípio educativo e pedagógico" àquela "fração dos intelectuais que é a mais homogênea e a mais numerosa (os instrutores, do mestre elementar aos professores de universidade)". Não especulo para sustentar uma tese; veja-se a mensagem de Armando de Salles Oliveira à Assembléia Legislativa em 1935 e lá se encontrará a afirmação de que a Faculdade fora criada para formar esses professores, além de pesquisadores Era por intermédio deles que Júlio de Mesquita Filho pretendia fazer a sua "revolução", e era por intermédio deles que o Partido da Ordem pretendia conservar a dominação dos espíritos.

Com toda certeza, os professores que passaram a integrar a coterie não tinham idéia do projeto pedagógico-político do Estado; sabiam apenas que o jornal era importante para defender a faculdade onde trabalhavam e, sobretudo, para defender a sua liberdade de cátedra, vale dizer, a possibilidade de continuar ensinando a pensar com liberdade. Nessa relação entre uma pessoa que tinha um projeto que pretendia mudar as mentalidades e os professores contratados no exterior ou aqui encontrados (como essa figura extraordinária que foi Fernando de Azevedo), deu-se um fato curioso: o jornal tomou o partido daqueles que dele se acercavam em busca de amparo político e passou a sustentar suas posições na luta que a Faculdade travava para ser tratada em pé de igualdade com as grandes 
escolas no Conselho Universitário e na luta intramuros, que havia e sempre houve.

Assim como havia a coterie Estado, havia a outra, a que se constituíra na Faculdade e influenciava o jornal, e que Júlio de Mesquita Filho tinha como a que representava seus ideais. Ela se reunia em torno dos nomes das ciências humanas e da filosofia: Fernando de Azevedo, que tinha Antonio Candido, Florestan Fernandes e depois Ruy Coelho como assistentes, na sociologia, Cruz Costa e Lourival Gomes Machado na filosofia e na política, Eurípides Simões de Paula, o "capitão" que viera da FEB, e Eduardo França, que haviam aprendido o ofício de historiador com Braudel. Uma coterie que lançava seus pseudópodos para a biologia e a química, procurava isolar os que, em outras cadeiras, não pensavam igual, e sempre impediu que aqueles que pensavam de maneira diferente à filosofia e se reuniam em torno de Miguel Reale no Instituto Brasileiro de Filosofia ocupassem cátedras na Faculdade.

Voltando aos "fundadores". A Cidade Universitária, no campus de São Paulo, traz o nome de Armando de Salles Oliveira; no cinqüentenário de fundação da Universidade, inaugurou-se um busto de Júlio de Mesquita Filho, homenagem tardia a quem idealizara a universidade e lutara para que escapasse das influências da baixa política paulista durante certa época. Nas várias escolas da USP pouco se sabe deles e, muitas vezes, se os têm como representantes daquilo que São Paulo pode ter produzido de retrógrado nos anos 30: típicos membros da oligarquia. Façamos sobre eles o juízo político que quisermos, o que mais nos convenha na luta ideológica. Não podemos, porém, julgá-los e condená-los pelo que não eram quando idealizaram a Universidade e a Faculdade de Filosofia, especialmente ela; tenhamos, pelo menos, o cuidado (que diria sociologicamente correto) de registrar que os intelectuais do Partido da Ordem que perfilavam as idéias, então hegemônicas, da Igreja Católica tinham os que pertenciam ao grupo do Estado, especialmente à família Mesquita, como adversários, "maçons", e que os autoritários que acabaram por triunfar em 1937 os viam não como homens do passado que se fazia mister superar, mas como rivais na disputa pela transformação do Brasil que despertara do seu secular sonho em 1930. Rivais, não por serem, os derrotados em 37 , liberais e eles, os triunfadores, autoritários. Rivais, sim, porque tinham do mundo e das soluções possíveis nos anos 30 uma visão muito parecida - com uma diferença que um sociólogo da política saberá valorizar: os triunfadores, vindos do Sul e do castilhismoborgismo, acreditavam na função diretora do Estado, encarnado na pessoa do Chefe. Os paulistas que perderam (pois não foram todos) igualmente criam na função dirigente do Estado, que só poderia efetivar-se por meio de um partido rigidamente disciplinado e que seria a estrada pela qual correriam os diferentes rios da Federação para desaguar, unidos, no mar brasileiro, as Forças Armadas firmemente disciplinadas e colocadas a serviço do Estado. Armando de Salles Oliveira, a grande vítima política do 10 de novembro de 1937, não se cansou, em sua campanha eleitoral e na sua política como governador, de mostrar-se assim, sem ambages, adversário dos comunistas de 1935 , político que proclamava o fim do liberalismo econômico e reclamava, ao fundar, juntamente com outros, a Escola Livre de Sociologia e Política, que a administração do Estado fosse racional.

Oligarcas, os fundadores da Universidade e da Faculdade não eram. Liberais, muito menos. O grupo em que formavam Armando de Salles Oliveira e Júlio de Mesquita Filho tem sido apontado, em praticamente todos os estudos sobre a Revolução de 30, como integrado por representantes da oligarquia paulista, os que fizeram a Revolução de 32 para buscar recuperar posições perdidas na República. Ora, os que haviam perdido em 30 , objetivamente, tinham sido os seguidores do PRP, não os democráticos de São Paulo. Creio que essa interpretação errada se deve à lente através da qual se vêem os pró-homens do Partido Democrático-ela está desfocada. Eles não eram oligarcas, mas sim aristocratas que pretendiam salvar o que restava do que jul- 
gavam ser a sua “civilização”, ameaçada a um tempo pelo coletivismo, como diria Armando de Salles Oliveira, e também pelo processo de urbanização que começava a mostrar sua face pouco "civilizada" na ação dos imigrantes que insuflavam estranhas idéias no meio operário, introduziam comportamentos não comuns na classe média que começava sua ascensão e, mais grave para eles, conseguiam fazer que o português começasse a ser deturpado por barbarismos, "italianismos" que depois se incorporaram à linguagem corrente. Mas eram mais do que isso - tinham também o seu lado romântico. Na greve geral que houve em São Paulo, em 1917, Júlio de Mesquita Filho foi escolhido como mediador entre as partes em conflito. E, no fim dos anos 50 ou começo dos 60 , quando nossa intimidade já permitia esse tipo de confidência, seu filho Luis Carlos dizia com certo orgulho que o ideal não realizado do pai tinha sido fundar um partido como o Labour Party inglês. Eram aristocratas, sim, tinham um certo ar romântico, mas tinham ainda algo mais: eram ilustrados. E, com certeza, pertenciam à Bucha, sociedade secreta que os entendidos dizem ter tido uma grande influência na vida paulista. A Bucha era uma sociedade secreta, e por isso mesmo é difícil escrever alguma coisa sobre ela com um relativo grau de certeza. Mas, pelo que se dizia, seus ideais eram os dos "iluminados da Baviera", uma sociedade fundada em 1776, depois aproximada à franco-maçonaria, que tinha por objetivo, assim dizem os dicionários, assenhorear-se da Autoridade e dela servir-se para ilustrar as pessoas. A educação era o instrumento preferido desses homens.

Os homens do Partido Democrático que sobrenadam na crise se consideravam liberais, mas não eram liberais no sentido em que hoje tomamos a palavra. Eram "ilustrados". Inspirado por Júlio de Mesquita Filho, Armando de Salles Oliveira funda a Faculdade de Filosofia. Um adversário da modernização não criaria uma escola de ensino superior para formar professores secundários trazendo do exterior os professores que formariam esses mestres sem antes examinar suas concepções do mundo. Menos ainda fundaria uma escola gratuita, em que, tendo méritos, qualquer cidadão poderia se matricular e por ela se formar.

Aqueles "iluminados" acreditavam no café, mas também na policultura, no plantio de culturas menos nobres do que o café, mas igualmente rendosas; na indústria e no comércio. Eram homens que confiavam no Exército como garante da democracia (que pretendiam fosse um regime político forte dirigido por um partido ferreamente disciplinado, que estaria à testa de um governo fiscalizado por assembléia eleita e instalado pelo voto secreto); que acreditavam que apenas um partido nacional poderia ser o instrumento da equalização da diferença política relativa dos diferentes estados e, sobretudo, que acreditavam que a educação permitiria a solução dos problemas mais urgentes da nação.

Armando de Salles Oliveira representava um Brasil diferente daquele que se cristalizara na República Velha. Ele se considerava um democrata, até mesmo um liberal, mas a democracia que tinha como necessária e possível não era igual àquela que conhecemos hoje. Ele, como muitos outros pensadores e políticos que formaram no Partido Democrático, queria construir um país diferente daquele em que vivia e que se aproximasse o quanto possível da Europa e dos Estados Unidos (o New Deal estava reformulando todos os conceitos da democracia liberal clássica). Os ventos que sopravam do Norte não traziam idéias liberais. Eram precursores de idéias e movimentos que sustentavam a defesa da Ordem contra o comunismo russo e, sobretudo, traziam a informação de que apenas um partido forte, organizado nacionalmente, poderia salvar o Estado.

Nesse sentido, é importante ter presente, quando se pretende situar o grupo de Armando de Salles Oliveira e Júlio de Mesquita Filho, que o governador e candidato tinha a mesma visão do Brasil e das soluções para seus problemas que o general Pedro Aurélio de Góes Monteiro, que vai ser o Condestável do Estado Novo. A 
diferença entre eles é que, ao contrário de Armando de Salles Oliveira, o general Góes Monteiro subordinava a solução dos problemas do Brasil àquilo que chamava de "política do Exército", querendo com isso significar que as políticas públicas deveriam pautar-se pelas exigências da mobilização militar. Mas defendia, também ele, a criação de um partido nacional e a realização de um esforço concentrado na educação...

São Paulo levantou-se em armas, em 1932, contra o Governo Provisório e em defesa da Constituição. Seis anos depois, a capital acolheu o ditador de fato e de direito que vinha inaugurar obras na cidade. Treze anos depois da Revolução Constitucionalista, o Estado elegeu Getúlio Vargas senador. Não é de estranhar, assim, considerando as alterações na morfologia social, especialmente na demografia (devendo destacar-se a composição do meio social interno, como diria Durkheim), que a Faculdade de Filosofia tenha mudado à medida que a cidade se transformara e que a capital fora reformada pelas mãos de Prestes Maia. Note-se que não apenas a urbe sofrera transformações profundas; também a pólis estava sofrendo com as mudanças que, imperceptivelmente, propiciariam a irrupção das grandes transformações políticas dos anos 50 e 60. Em 1950, convém não esquecer, o Censo pela primeira vez acusava que o Brasil se tornara um país urbano.

A coterie dos fundadores tinha de sofrer as conseqüências de todas essas mudanças. Nas relações entre o jornal e a coterie intramuros poderia aplicar-se a "lei das proporções definidas" que Gramsci retoma de Pantaleone: “Quimicamente, os corpos combinam-se unicamente em proporções definidas e qualquer quantidade de um elemento que supere a quantidade exigida para uma combinação com outros elementos, presentes em quantidades definidas, permanece livre; se a quantidade de um elemento é deficiente em relação à quantidade de outros elementos presentes, a combinação só se dá na medida em que é suficiente a quantidade do elemento que está presente em quantidade menor do que a dos demais" (in Gramsci, Caderno 13, § 31). Traduzida para a realidade que busco retratar (com o viés assinalado no início), poderia dizer, repetindo o que escrevi alhures: “[...] a ação da elite que se constitui com vistas a transformar a concepção do mundo vigente ou a conservá-la será sempre condicionada [...] ao número dos quadros dirigentes e dos ativistas (mais do que isso, da independência moral, maior ou menor, dos que estão na periferia da organização) e ao volume da massa que se busca atingir. [A] hegemonia é uma questão de ampliação da base social do grupo dirigente".

Até 1955, não fora difícil a relação entre o círculo que gravitava em torno dojornal e a coterie intramuros. Politicamente contrários, ainda que as razões fossem diversas, aos grupos politicamente dominantes - Ademar de Barros e Lucas Nogueira Garcez em São Paulo, o marechal Eurico Gaspar Dutra e Getúlio Vargas no plano federal - nada impedia que as relações pessoais fossem além do que se poderia chamar de civilizadas. Havia mais do que simplesmente a preocupação com as formas nas relações sociais impostas pela colaboração que muitos dos professores prestavam ao jornal; a pertença a determinados círculos sociais comuns fazia que as diferenças de concepções do processo político brasileiro não prejudicassem o relacionamento pessoal, pelo contrário. Em 1955, a semelhança, para não dizer a identidade de pontos de vista diante dos golpes de Estado que marcaram o mês de novembro (a deposição dos presidentes Carlos Luz e Café Filho a 11 e 21 daquele mês), evidenciouse na postura editorial do jornal e no manifesto que a Congregação da Faculdade de Filosofia aprovou condenando a "novembrada" do general Teixeira Lott. A marcha dos acontecimentos mudou tudo, porém e levou ao rompimento da solidariedade interna da "coterie Estado" e daquela intramuros. É que, na verdade, a "coterie 
Estado" não tinha, na Universidade e até mesmo na Faculdade, ampliado sua base social de apoio. Vencida a fase de afirmação da liberdade de propagar o "verdadeiro método de ensinar" - que se conquistara com a consolidação do processo democrático formal de 1946 - a coterie perdeu, para o conjunto da Faculdade, sua razão de ser. O antigo aliado - que ainda seria de capital importância na luta que a Faculdade travou contra o governador Jânio Quadros em defesa de Mário Schenberg e João Cruz Costa - passou a ser visto, depois de 1950 , não mais em função do que representara nas escaramuças contra a São Paulo antiga, mas das divisões internas e das posições que o jornal assumia na luta política nacional. Ao mesmo tempo, no longo processo de afirmação da Faculdade, os que integravam a coterie intramuros foram ficando em minoria e passaram a ser vistos não como o canal de comunicação com quem defendia o verdadeiro método de ensinar, mas como o "grupo do Estado". Curiosamente, a maioria não se apercebeu de que aqueles que integravam a coterie intramuros também não se apresentavam mais unidos, fosse porque a grande luta fora vencida, fosse porque o turbilhão político externo já começava a separar uns de outros em função de posições políticas, para não dizer ideológicas. Em 1964, a separação se tornou evidente.

A cisão na coterie intramuros deu-se aos poucos, e o primeiro sinal de que o cristal um choque sofrera não foi percebido como tal, porque a disputa era teórica, em torno do conceito de classes sociais, em 1948. Mas deixou seqüelas, que foram se mostrando como sintomas daquela que é a sedução mais forte que pode corroer amizades e a solidariedade grupal, a luta pelo poder.

Depois do sítio em que a Maria Antônia foi submetida por milícias privadas sem que o Estado impusesse sua vontade, a Faculdade já não era a mesma de quando o jovem estudante a ela se chegou, em 1947, temeroso de adentrar o centro do saber. Batida, dividida, sem apoio externo, não pôde refazer sua história - sobretudo porque nos

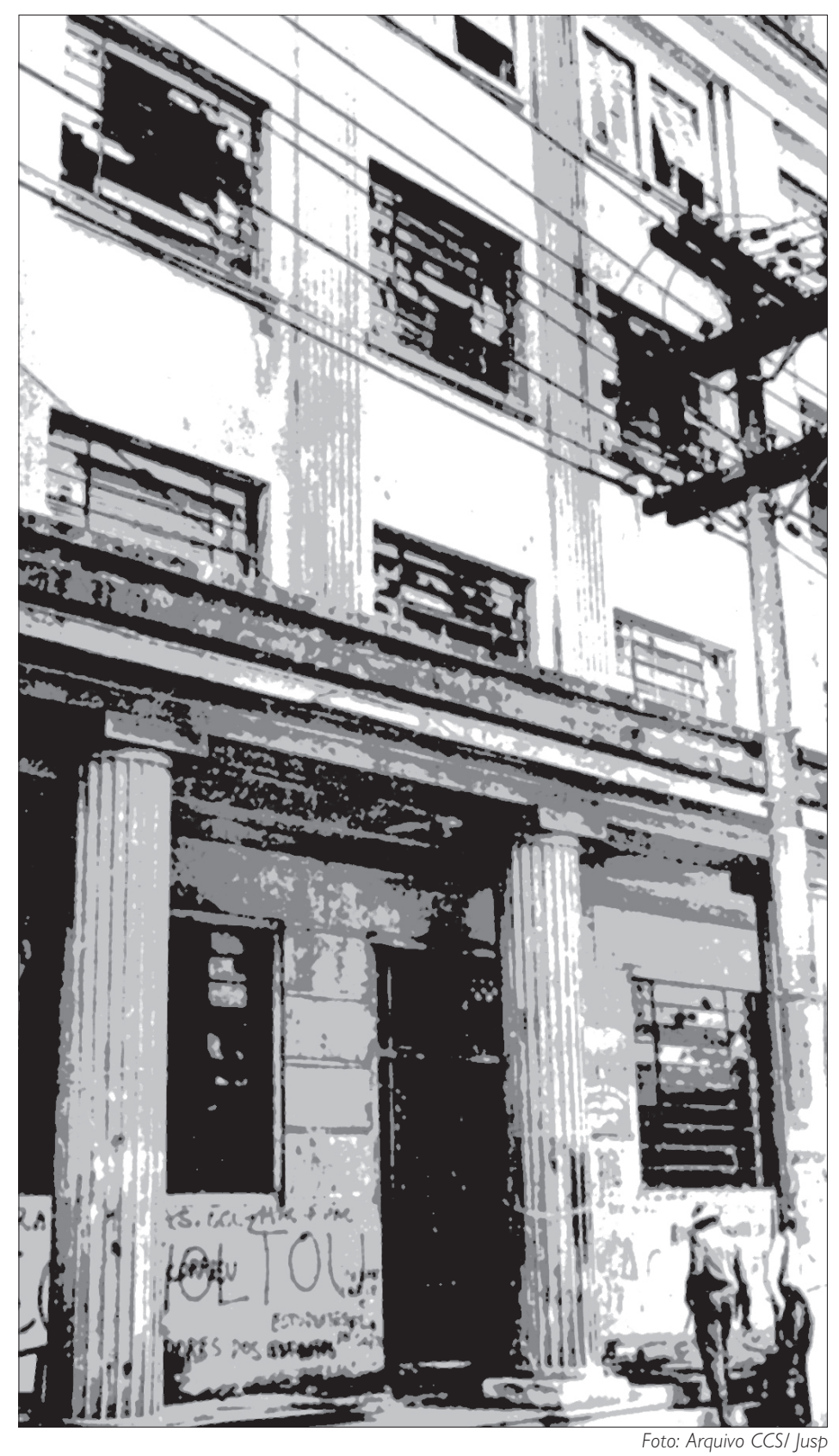

barracões da Cidade Universitária, para onde foi jogada em solução de emergência, foi de novo golpeada, no que tinha de melhor, pelos grupelhos que se haviam apoderado do poder do Estado. Sobre ela se tentou lançar o esquecimento - e foi preciso a resistência de todos, mas especialmente de Eurípides Simões de Paula, o "capitão”, depois de Ruy Coelho (ele também vítima) e dos bedéis, entre os quais Salvador Oricchio, para que vivesse até hoje como projeto integrado por memórias e não por visões do futuro. 